Volume 2, Nomor 1, Tahun 2020 Hal 301 - 311

\title{
Pemanfaatan Material Daur Ulang untuk Pengembangan Karya Seni dan Kerajinan di Kelurahan Kebon Pala Kecamatan Makasar Jakarta Timur
}

\author{
Sri Pare Eni ${ }^{1}$, Galuh Widati ${ }^{2}$, Margareta M. Sudarwani ${ }^{3}$ \\ 123 Universitas Kristen Indonesia, Jakarta, Indonesia \\ E-mail: sri.eni@uki.ac.id; galuh.widati@uki.ac.id; margareta.sudarwani@uki.ac.id
}

\begin{abstract}
Abstrak
Program pengabdian pada masyarakat dilaksanakan dalam berbagai bentuk dalam rangka pendampingan pembinaan kampung hijau. Pendampingan pembinaan kampung hijau di kelurahan Kebon Pala Jakarta Timur juga telah dilaksanakan sejak tahun 2015. Masyarakat di kelurahan Kebon Pala sudah lebih peduli terhadap kebersihan lingkungan nya sehingga pendampingan berupa penyuluhan dan pelatihan yang dilakukan di Kebon Pala bisa langsung dirasakan manfaatnya. Terbukti dengan pelatihan membuat kreativitas bambu untuk penghijauan, lukisan untuk penghijauan dapat segera dilaksanakan oleh masyarakat. Jenis pengabdian pada masyarakat yang akan dibahas di sini termasuk dalam kategori "pemberdayaan masyarakat" melalui pelatihan kreativitas membuat kerajinan dari bahan / material daur ulang sampah dan atau pemanfaatan material alami lokal menjadi sesuatu barang yang berguna, berharga dan mempunyai unsur seni. Dalam pembinaan kampung hijau di Kelurahan Kebon Pala, di bina juga unsur kemandirian masyarakat melalui pemberdayaan ibu ibu dalam berkreasi dengan bahan daur ulang, serta mengembangkan usaha kecil seperti budi daya tanaman Lidah buaya dan tanaman obat untuk jamu dan berbagai makanan kecil. Generasi muda, karang taruna dan anak anak di kelurahan Kebon Pala sangat aktif dengan berbagai kegiatan, oleh sebab itu sangat positip jika sedari kecil anak anak sudah diperkenalkan budaya cinta lingkungan, pengelolaan limbah lingkungan dengan baik bahkan memanfaatkannya menjadi benda bernilailainnya.
\end{abstract}

Kata Kunci: karya seni dan kerajinan, Kebon Pala, material daur ulang, pemanfaatan.

\begin{abstract}
Community service programs are carried out in various forms in the context of assisting in fostering green villages. Since 2015 the assistance for green village development has also been carried out in the Kebon Pala village in East Jakarta. The people in Kebon Pala village are already more concerned about the cleanliness of their environment so that the assistance in the form of counseling and training conducted at Kebon Pala can be felt immediately. Evidenced by the training to make bamboo creativity for greening, painting for greening can be immediately carried out by the community. The type of community service that will be discussed here is included in the category of "community empowerment" through creativity training in making handicrafts from waste recycling materials and or utilizing local natural materials into something useful, valuable and has elements of art. In the fostering of a green village in Kebon Pala Village, community self-reliance is also fostered through the empowerment of women in creating creativity with recycled materials, as well as developing small businesses such as aloe vera plant cultivation and medicinal plants for herbs and various small foods. Young people, youth groups and children in Kebon Pala village are very active in various activities, therefore it is very positive if children have been introduced to a culture of environmental love, good management of environmental waste and even use it to become a valuable object.
\end{abstract}

Keywords: art and crafts, Kebon Pala, recycling materials, utilization. 
Volume 2, Nomor 1, Tahun 2020 Hal 301 - 311

\section{PENDAHULUAN}

\subsection{Latar Belakang}

Volume sampah rumah tangga selalu terjadi peningkatan, jika tidak dikelola dengan baik, akan memiliki dampak terhadap kesehatan manusia dan lingkungan. Akibat dari semakin bertambahnya tingkat konsumsi masyarakat dan aktivitas lainnya maka bertambah pula limbah yang dihasilkan, limbah tersebut pada akhirnya menjadi permasalahan lingkungan. Apabila mendengar kata sampah yang terlintas dibenak kita adalah membuangnya ke tempat sampah, tetapi untuk membuangnya mesti harus dipilah mana sampah organik, mana sampah non organik, dan mana sampah B3 (bahan beracun berbahaya). Dalam UndangUndang Nomor 18 Tahun 2008 tentang Pengelolaan Sampah disebutkan bahwa sumber penghasil sampah sudah harus melakukan prinsip pemilahan dan life circle sampah yang berupa reduce (mengurangi), reuse (menggunakan ulang), dan recycle (mendaur ulang). Pemilahan ini merupakan kesibukan yang kreatif karena dengan memilah sampah organik misalnya, bisa menghasilkan pendapatan apabila dibuat kompos yang akan menghasilkan sayuran, buahbuahan. Hal ini berarti pula bisa membuat hidup lebih hemat. Jika kita memilih limbah plastik dihancurkan menjadi butiran plastik kembali, tidak mungkin karena memerlukan energi yang lebih banyak dibanding saat proses produksi, bisa menimbulkan kerugian. Maka kita bisa mendaur ulangnya menjadi kerajinan tangan untuk keperluan sehari-hari. Karena proses ini lebih mudah, bisa mengasah kreativitas dan bisa menghasilkan tambahan uang. Agar sampah tidak semakin bertambah, apalagi sampah plastik merupakan jenis sampah yang sangat sulit terurai, solusinya: meminimalisir penggunaan bahan plastik, membawa tas yang bisa dipakai berkalikali dari rumah saat berbelanja, diubah kembali ke dalam butiran plastik, mengganti bungkus makanan dengan bahan organik, didaur ulang dibuat sebagai karya seni dan kerajinan tangan, dilakukan pembakaran.

Untuk meminimalisir volume sampah perlu dilakukan pengelolaan sampah melalui pemanfaatan sampah dan mendaur ulang sampah melalui kegiatan pemanfaatkan sampah untuk dibudidayakan menjadi kreasi seni dan karya kerajinan dari bahan daur ulang di Kota Administrasi Jakarta Timur khususnya Kelurahan Kebon Pala melalui program Green Action di tahun 2019.

Seperti kebanyakan kegiatan ibu-ibu PKK saat ini kreativitas kerajinan dari 
Volume 2, Nomor 1, Tahun 2020 Hal 301 - 311

sampah juga berkembang baik di Kelurahan Kebon Pala. Selain itu di ingkungan juga tersedia banyak pohon dan tanaman sebagai wujud penghijauan kampung. Masyarakat bisa memanfaatkan beberapa tanaman untuk di budidayakan menjadi bahan kerajinan yang menarik, unik dan belum banyak di perkenalkan, Selain itu ibu ibu PKK sambil membersihkan halaman juga bisa mengumpulkan daun daun kering dan sampah yang bisa dimanfaatkan juga sebagai kombinasi di dalam karya kreativitas Seni dan kerajinan. Dalam program Green Action sebelumnya masyarakat, ibu-ibu, karang taruna dan anak anak dilibatkan dalam kegiatan membuat karya seni dan kerajinan dari bahan daun transparant, daun kering dan juga bahan dari limbah. Kali ini RW 09, kelurahan Kebon Pala mengajukan permohonan kepada Prodi Arsitektur UKI untuk mengadakan workshop pelatihan dan lomba dalam hal kreasi seni dan karya kerajinan dari bahan daur ulang untuk anak anak sekolah tingkat Sekolah Dasar (SD) dan Tingkat Sekolah Menengah Peertama (SMP). Hal ini merupakan bagian dari program Kelurahan Kebon Pala menuju kampung Proklim dimana seluruh masyarakatnya sejak usia dini diperkenalkan untuk peduli kepada pengelolaan lingkungan yang bebas dari sampah/ limbah.

Tujuan kegiatan pengabdian ini adalah untuk dapat: Memberikan motivasi terhadap partisipasi aktif masyarakat dalam bentuk workshop, pelatihan dan pendampingan kegiatan; Membangun hubungan kemitraan dan kerjasama dengan masyarakat, pemerintah daerah dan dunia usaha serta pihak-pihak terkait lainnya dalam rangka mengembangkan jaringan dan meningkatkan dukungan bagi pengembangan kawasan dan keberlanjutan pemberdayaan masyarakat. Sedangkan Sasaran yang ingin dicapai dari pelaksanaan kegiatan ini adalah: Terbentuknya kemampuan masyarakat untuk dapat mengidentifikasi potensi dan permasalahan lingkungan, serta mengatasi dan memecahkan masalah tersebut berdasar pada segenap potensi lokal dan daya kemampuan yang dimiliki; Terwujudnya proses pendampingan secara terstruktur dan proses pemberdayaan masyarakat secara berkesinambungan dengan cara meningkatkan kesadaran, partisipasi aktif, peningkatan kreativitas dan kemampuan masyarakat melalui pelatihan-pelatihan yang dilaksanakan, agar kegiatan ini dapat berkelanjutan di masa yang akan datang. 


\subsection{Permasalahan}

Potensi yang menonjol khususnya di RW 09 kelurahan Kebon Pala, adalah aktifnya masyarakat dalam berkegiatan baik pemeliharaan lingkungan, kegiatan PKK, Kesehatan, Olah Raga maupun kesenian. Terlebih ibu-ibu PKK sudah banyak menghasilkan produk olahan Rumah Tangga yang bisa meningkatkan ekonomi Rumah Tangga. Namun dibalik itu, anak-anak belum terlalu dilibatkan dalam kegiatan khususnya dalam pemeliharaan lingkungan. Sehingga golongan anak-anak sering buang sampah sembarangan. Anak-anak perlu ikut serta diberikan pembinaan untuk menjaga kebersihan. Mengenali unsur positif dan negatif sampah bagi kehidupan manusia. Perlu diberikan program khusus dimana anak-anak juga sudah wajib ikut memelihara kebersihan dan kesehatan lingkungan dari sampah. Diperkenalkan cara dan teknik pengelolaan sampah hingga memanfaatkannya untuk daur ulang menjadi benda yang berguna dan berharga.

\subsection{Program}

Program pengabdian pada masyarakat di Kelurahan Kebon Pala ini dimaksudkan untuk mengembangkan sumberdaya manusia dan lingkungan melalui pemanfaatan potensi local dengan cara:

a. Memperkenalkan berbagai jenis sampah lingkungan dan pengelolaannya,

b. Menunjukkan berbagai olahan sampah menjadi berharga,

c. Membuat workshop pelatihan berkreasi dengan sampah menjadi karya seni dan kerajinan,

d. Mengadakan Lomba hasil kreativitas dan kerajinan.

\subsection{Target}

Target yang dicapai pada kegiatan pengabdian pada masyarakat di Kelurahan Kebon Pala Kecamatan Makasar Jakarta Timur ini adalah:

a. Membuat kegiatan penyuluhan kepada anak-anak sekolah tentang jenis sampah, limbah, aspek negatif dan positip nya, serta pengelolaan nya.

b. Memperkenalkan berbagai contoh budi daya sampah yang mendatangkan berkah bagi lingkungan.

c. Mengadakan workshop pelatihan membuat kreativitas karya seni dan kerajinan dari nsampah/limbah untuk anak SD dan SMP di RW 09 Kelurahan Kebon Pala, Jakarta Timur. 
Volume 2, Nomor 1, Tahun 2020 Hal 301 - 311

d. Mengadakan evaluasi/lomba hasil kreativitas seni dan kerajinan bagi para peserta workshop.

\subsection{Luaran}

Adapun luaran yang diharapkan adalah sebagai berikut :

a. Dapat memotivasi semangat kewirausahaan dari usia dini,

b. Memanfaatkan sumberdaya usia produktif maupun anak-anak untuk membuat sebuah kreativitas dan usaha yang selama ini menjadi potensi kelurahan Kebon pala,

c. Mengurangi tenaga kerja pengangguran utamanya kaum perempuan yang sudah memiliki ketrampilan.

\section{METODE}

Pendekatan yang digumakan dalam pelaksanaan kegiatan meliputi: 1) Participatory yang bertujuan untuk menyerap Partisipasi Aktif Masyarakat dalam rangka keterlibatan dalam kegiatan ini. Kondisi ini dapat diukur dari banyaknya masyarakat yang menghadiri kegiatan pertemuan yang dilaksanakan serta keaktifan mereka dalam rangka memberikan pertanyan, masukkan dan usulan kepada nara sumber untuk dibahas bersama-sama; 2) Community Empowerment, dimana kegiatan dilakukan dengan melibatkan seluruh elemen dalam masyarakat secara aktif dari mulai tahap observasi, penyusunan rencana sampai dengan tahap pelaksanaan.

Metode yang digunakan untuk rencana pelaksanaan pengabdian pada masyarakat ini adalah sebagai berikut:

a. Penyuluhan dengan Slide Projector dan menunjukkan contoh-contoh,

b. Pelatihan membuat Karya Seni dan kerajinan (dengan demonstrasi pembuatan karya seni/ misalnya membuat lukisan dari bungkus sabun),

c. Mengevaluasi dan mengadakan lomba/kompetisi untuk mendapatkan 3 karya seni terbaik bagi setiap tingkat sekolah (SD, SMP).

\section{HASIL DAN PEMBAHASAN}

Program Green Action merupakan Program Pengabdian pada Masyarakat yang mulai dilaksanakan oleh Program Studi Arsitektur Fakultas Teknik Universitas Kristen Indonesia (UKI) sejak bulan Mei 2009. Program ini adalah kelanjutan dari program di tahun-tahun sebelumnya. Berikut disajikan tabel program kegiatan pengabdian pada masyarakat yang dimulai dari tahun 2009 sampai dengan tahun 2019. 
Volume 2, Nomor 1, Tahun 2020 Hal 301 - 311

Tabel 1. Program Pengabdian Pada Masyarakat Prodi Arsitektur UKI

\begin{tabular}{|c|c|c|}
\hline No. & Year & Activity Name \\
\hline 1 & $2009-2010$ & Penyuluhan kampung Hijau Binaan UKI \\
\hline 2 & $2011-2012$ & $\begin{array}{l}\text { Sosialisasi, Lomba Kreasi Hijau, Penyuluhan \& Workshop } \\
\text { tentang pengelolaan sampah, Pengecatan Fasade Dinding } \\
\text { Unit Rumah Tinggal pada satu gang yang terpilih }\end{array}$ \\
\hline 3 & 2013-2014 & $\begin{array}{l}\text { Pengelolaan Sampah, Evaluasi Kondisi Kawasan Kelurahan } \\
\text { Cawang, Pengelolaan Sistem Operasional Bank Sampah, } \\
\text { Lomba Kreasi Lingkungan Hijau dan Kreativitas Daur Ulang } \\
\text { dari sampah, Pengelolaan Sampah Organik \& Non organic, } \\
\text { Bank Sampah }\end{array}$ \\
\hline 4 & $2015-2016$ & $\begin{array}{l}\text { Penyuluhan kampung Hijau dengan hidroponik, Sosialisasi } \\
\text { Lomba Lingkungan Hijau dan pembagian material, Evaluasi } \\
\text { bank sampah, Penyuluhan tentang energi terbarukan, Lomba } \\
\text { Lingkungan Hijau. }\end{array}$ \\
\hline 5 & $2017-2018$ & $\begin{array}{l}\text { Penyuluhan kampung Hijau, Komposting, Hidroponik dan } \\
\text { Greenwall Painting }\end{array}$ \\
\hline 6 & 2019 & $\begin{array}{l}\text { Penyuluhan dan Workshop tentang Komposting, Menanam } \\
\text { dengan Hydrophonic, mahasiswa melakukan kegiatan Green } \\
\text { Wall painting di Kelurahan Cawang }\end{array}$ \\
\hline 7 & 2019 & $\begin{array}{l}\text { Workshop dan pelatihan berkreasi dengan sampah menjadi } \\
\text { karya seni dan kerajinan, Mengadakan lomba/kompetisi } \\
\text { untuk mendapatkan } 3 \text { karya seni terbaik bagi setiap tingkat } \\
\text { sekolah (SD, SMP) di Kelurahan kebon Pala }\end{array}$ \\
\hline
\end{tabular}

\subsection{Kajian Lokasi Pengabdian}

Kelurahan Kebon Pala terletak di Kecamatan Makasar Jakarta Timur. Lokasi tempat pengabdian masyarakat tepatnya di RT 09 RW 09 Kelurahan Kebon Pala dengan Batas Wilayah Administratif meliputi: Sebelah Selatan SMPN 275/TPU, Sebelah Barat RT. 008/09, Sebelah Utara RT. 013/09, dan Sebelah Timur RT. 010/09.

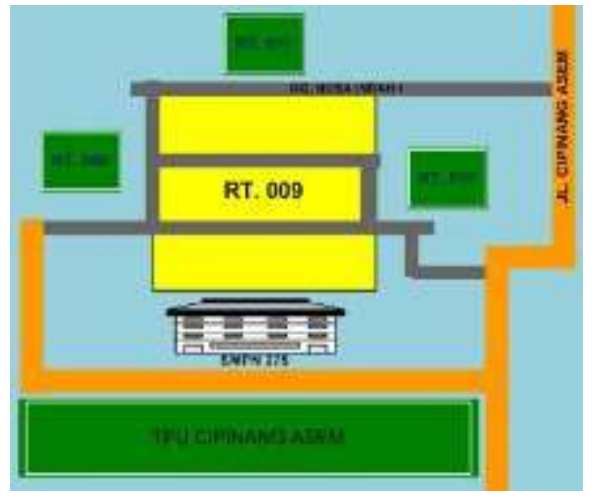

Gambar 1. Wilayah RT 09 RW 09 Kelurahan Kebon Pala
Jumlah Kepala Keluarga (KK) sekitar $57 \mathrm{KK}$ dengan jumlah warga total 221 jiwa, yang berjenis kelamin pria ada 114 orang, dan jenis kelamin wanita sejumlah 107 orang. Luas wilayah sekitar 6.470 M2 dan berasal dari Etnis Jawa, Sunda, Betawi, Batak, Minang, Menado. Komposisi penduduk RT 09 RW 09 kelurahan Kebon Pala berdasarkan agama menunjukkan bahwa pada tahun 2012 penduduk beragama Islam ada 201 jiwa dan penduduk beragama Krissten berjumlah 19 jiwa. Pada tahun 2013 penduduk beragama Islam ada 201 jiwa dan penduduk beragama Krissten berjumlah 19 jiwa. Pada tahun 2014 penduduk beragama Islam ada 202 jiwa dan penduduk beragama Krissten berjumlah 19 jiwa. Sedangkan kondisi penduduk berdasarkan mata pencaharian 
Volume 2, Nomor 1, Tahun 2020 Hal 301 - 311

terlihat bahwa 47,95\% penduduk RT 09 RW 09 Kelurahan kebon Pala bekerja sebagai pegawai swasta, sementara yang bekerja sebagai pegawai negeri sipil ada $13,70 \%$, pensiunan ada $08.22 \%$, pedagang $04,11 \%$, dan pekerjaan lain 26,02\%. Struktur Kepengurusan Rukun Tetangga RT 09 RW 09 Kelurahan Kebon Pala dapat dilihat pada gambar berikut:

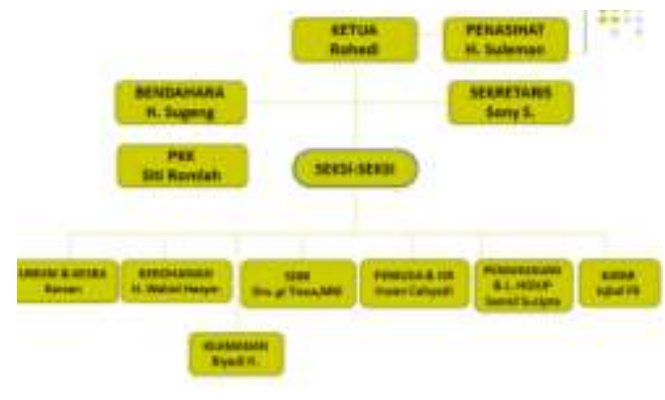

Gambar 2. Struktur Kepengurusan Rukun Tetangga RT 09 RW 09

\subsection{Pelaksanaan Kegiatan}

Pelaksanaan kegiatan pengabdian kepada masyarakat berjalan dengan lancar dan mendapat dukungan masyarakat. Sebelum dilaksanakan program kegiatan ini, Program Studi Arsitektur Fakultas Teknik Universitas Kristen Indonesia (UKI) membentuk panitia program kegiatan Pengabdian Pada Masyarakat. Kemudian dilaksanakan sosialisasi Program Green Action merupakan Program Pengabdian pada Masyarakat oleh Program Studi Arsitektur Fakultas Teknik Universitas Kristen Indonesia (UKI) diawali dengan sosialisasi yang diadakan di Ruang Puskrenov Fakultas Teknik yang dihadiri oleh perwakilan warga di rw 09 Kelurahan
Kebon Pala. Pada sub bab ini dibahas hasil yang dicapai dari beberapa rencana kegiatan pengabdian di kelurahan Kebon pala.

\section{a. Workshop dan Pelatihan}

Workshop dan Pelatihan adalah kegiatan yang disertai dengan demonstrasi atau percontohan untuk menghasilkan keterampilan tertentu. Workshop dan pelatihan bertema "Daur Ulang sampah menjadi karya seni dan kerajinan tangan" telah dilaksanakan pada hari Sabtu tanggal 30 November 2019 Pukul 09.00 di RT 09 RW 09 Kelurahan Kebon Pala Penyuluhan dihadiri oleh sekitar 50 warga, yang terdiri dari Ketua RW, pejabat Kelurahan Kebon Pala, (Bidang Lingkungan dan Ketua LMK) dan Ibu-ibu Kader PKK dan anak-anak SD serta SMP. Adapun rangkaian kegiatan workshop dan pelatihan dari program pengabdian masyarakat ini adalah doa pembuka, kata sambutan dari Ketua RW, kata sambutan dari ketua tim pengabdian masyarakat, pembekalan materi atau penyuluhan dari narasumber, penjelasan teknis lomba, pelaksanaan lomba, penilain oleh juri, dan terakhir pengumuman pemenang.

Pembekalan materi tentang "Sampah membawa Berkah" membahas tentang Sampah dan Barang Bekas dengan modal yang minim, bisa memperoleh hasil yang besar dengan dibuat sebagai hiasan melalui keahlian \& kreativitas yang bisa menghasilkan keindahan dan penghasil 
Volume 2, Nomor 1, Tahun 2020 Hal 301 - 311

rupiah. Juga bisa sebagai lapangan pekerjaan, menyediakan lapangan pekerjaan bagi warga sekitar, mengurangi angka pengangguran, dan menambah penghasilan tambahan. Kerajinan Dari Barang Bekas Yang Mudah Dibuat dan Bisa Dijual yaitu: 1) kerajinan tangan dari botol plastik atau kaleng bekas: dapat dibuat menjadi tempat untuk charger hp, boneka lucu, pot tanaman dari botol plastik, botol dibungkus dengan kertas kado yang unik, pot tanaman meja, tempat lampu, tempat pensil, bunga plastik, boneka, sandal, dompet plastik, gelang dari plastik, mobil dari botol kaleng bekas, ikan plastic, perahu dari botol plastic, dan lain-lain; 2) kerajinan tangan dari tutup botol bekas: dapat dibuat kalender dari tutup botol, kursi dari tutup botol, pernak-pernik dari tutup botol, kalung dari tutup botol kaleng, wajah hewan dari tutup botol, bunga, robot, dan lain-lain; 3) kerajinan tangan dari kardus bekas: dapat dibuat miniature rumah (maket), rumah kucing, lampu gantung, laptop stand, lampu belajar, kamera mainan, boneka, celengan, rumah burung, mobil mainan, kapal, topeng, robot kertas, dan lain-lain; 4) kerajinan tangan dari sedotan bekas: bisa dibuat bunga plastic, lampu Kristal, burung, kemoceng, dan lain-lain; 5) kerajinan tangan dari kain flannel: bisa dibuat bros bunga, boneka hias, sandal, dan lain-lain; dan 6) kerajinan tangan dari daun-daun kering: bisa dibuat menjadi daun transparan dari olahan daun yang tergolong keras uratnya direndam dengan lumpur untuk waktu 1 sampai 3 minggu dengan tujuan untuk menghilangkan khloropilnya, sehingga yang tertinggal adalah urat-urat daun transparan yang sangat bervariasi coraknya dan bisa diproses menjadi berwarna-warni. Kemudian dibentuk menjadi karya seni lukisan dua dan tiga dimensi. Daun transparan juga menjadi elemen hiasan peralatan rumah tangga, hiasan dinding, tas, patung dan lain-lain.
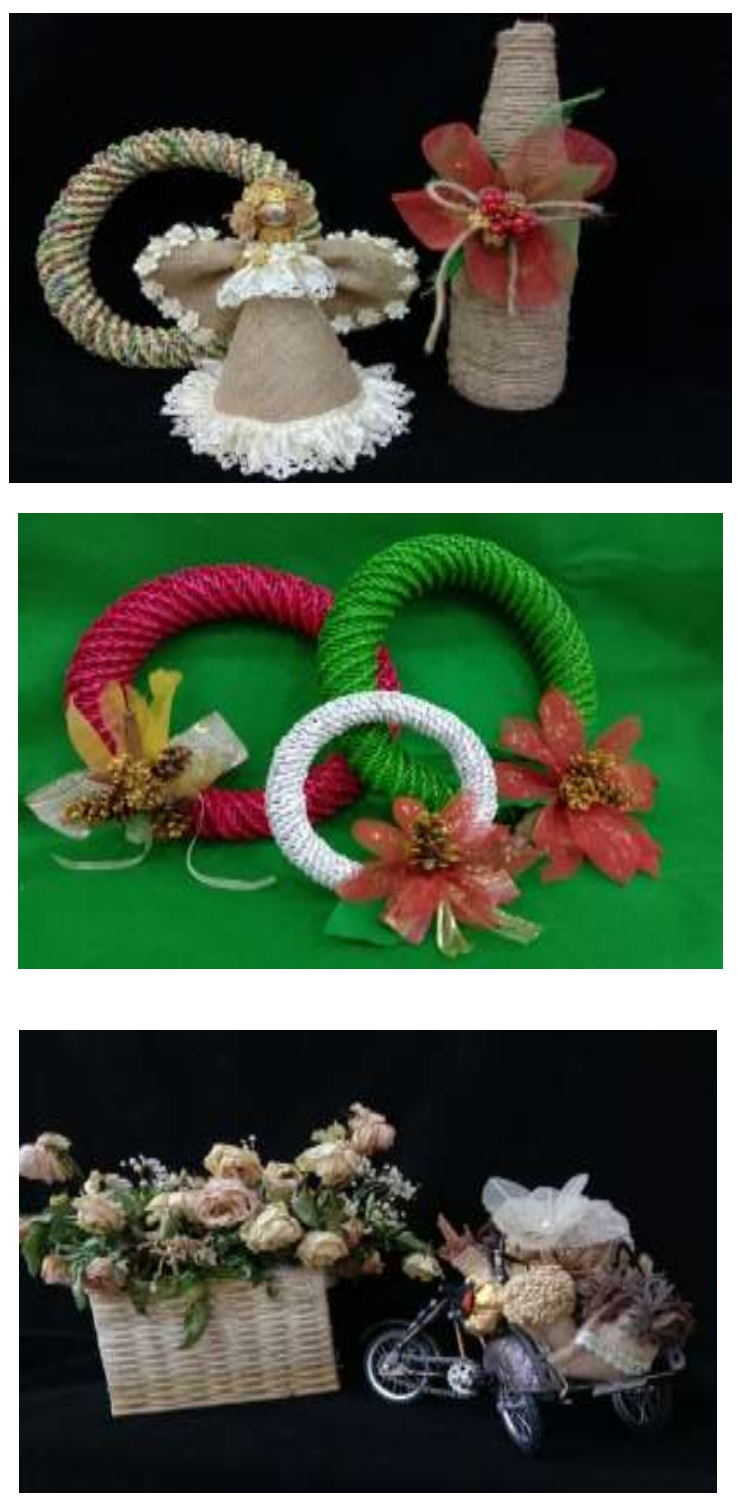

Gambar 3. Kerajinan Daun Transparan 
Volume 2, Nomor 1, Tahun 2020 Hal 301 - 311

Tujuan dari kegiatan ini adalah memberikan program khusus dimana anakanak sekolah juga sudah wajib ikut memelihara kebersihan dan kesehatan lingkungan dari sampah. Diperkenalkan cara dan teknik pengelolaan sampah hingga memanfaatkan nya untuk daur ulang menjadi benda yang berguna dan berharga. Hal ini merupakan bagian dari program Kelurahan Kebon Pala menuju kampung Proklim dimana seluruh masyarakatnya sejak usia dini diperkenalkan untuk peduli kepada pengelolaan lingkungan yang bebas dari sampah/ limbah. Dalam Workshop dan Pelatihan ini diperkenalkan berbagai jenis sampah lingkungan dan pengelolaannya, kemudian menunjukkan berbagai olahan sampah menjadi berharga. Workshop dan pelatihan mengajak anak-anak sekolah berkreasi dengan sampah menjadi karya seni dan kerajinan. Dalam workshop dan pelatihan tersebut juga diberikan pembekalan materi lomba tentang Kreativitas Karya Seni \& Kerajinan Dari Material Daur Ulang / Limbah Untuk Siswa SD \& SMP. Sebagai tindak lanjut dari kegiatan ini adalah diadakannya lomba tentang Kreativitas Karya Seni \& Kerajinan Dari Material Daur Ulang/Limbah Untuk Siswa SD \& SMP.

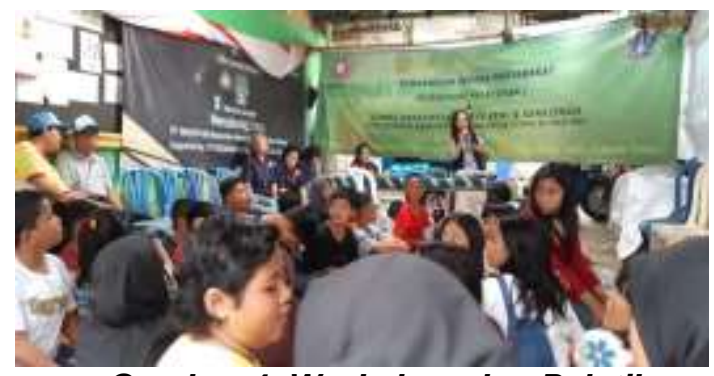

Gambar 4. Workshop dan Pelatihan

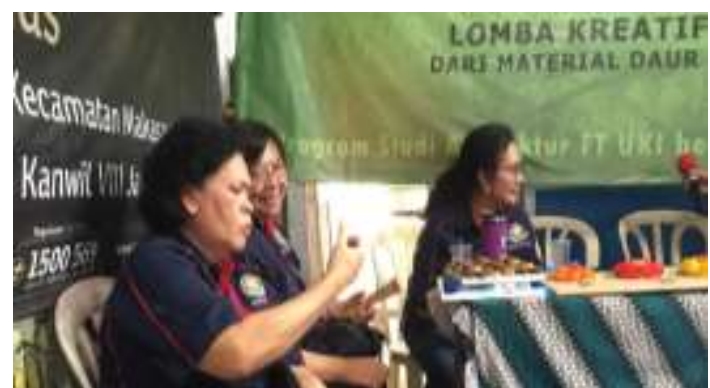

Gambar 5. Tim pengabdian Masyarakat

\section{b. Lomba Kreativitas Karya Seni \& Kerajinan}

Lomba tentang Kreativitas Karya Seni \& Kerajinan Dari Material Daur Ulang/Limbah Untuk Siswa SD \& SMP dilaksanakan di RT 09 RW 09 Kelurahan Kebon Pala pada hari Sabtu tanggal 30 November 2019 Pukul 10.30. Dalam ketentuan lomba setiap tim terdiri dari 2 Peserta. Pelaksanaan lomba diawali dengan penjelasan teknis lomba, dan dilanjutkan pelaksanaan lomba, penilaian oleh juri dan pengumuman pemenang lomba. Peserta lomba membawa bahan daur ulang (benar-benar bekas) berupa: 1) botol plastik/kaleng bekas, 2) tutup botol plastik/kaleng bekas, 3) bungkus plastik bekas (sabun bubuk, kopi, pelembut cucian), 4) Kertas kardus bekas, 5) Kertas kardus tissu rol bekas, 6) Sedotan bekas, dan 7) Tas plastik bekas. Kreasi kerajinan bisa dari salah satu atau kombinasi dari beberapa bahan no 1-7 di atas. Kreasi kerajinan berupa 2D (lukisan) atau kreasi 3D. Peserta diharap membawa peralatan sendiri berupa: gunting, cutter, kawat, alat tulis(misalnya pencil atau penggaris), sedangkan lem tembak dan lem fox disediakan panitia. 


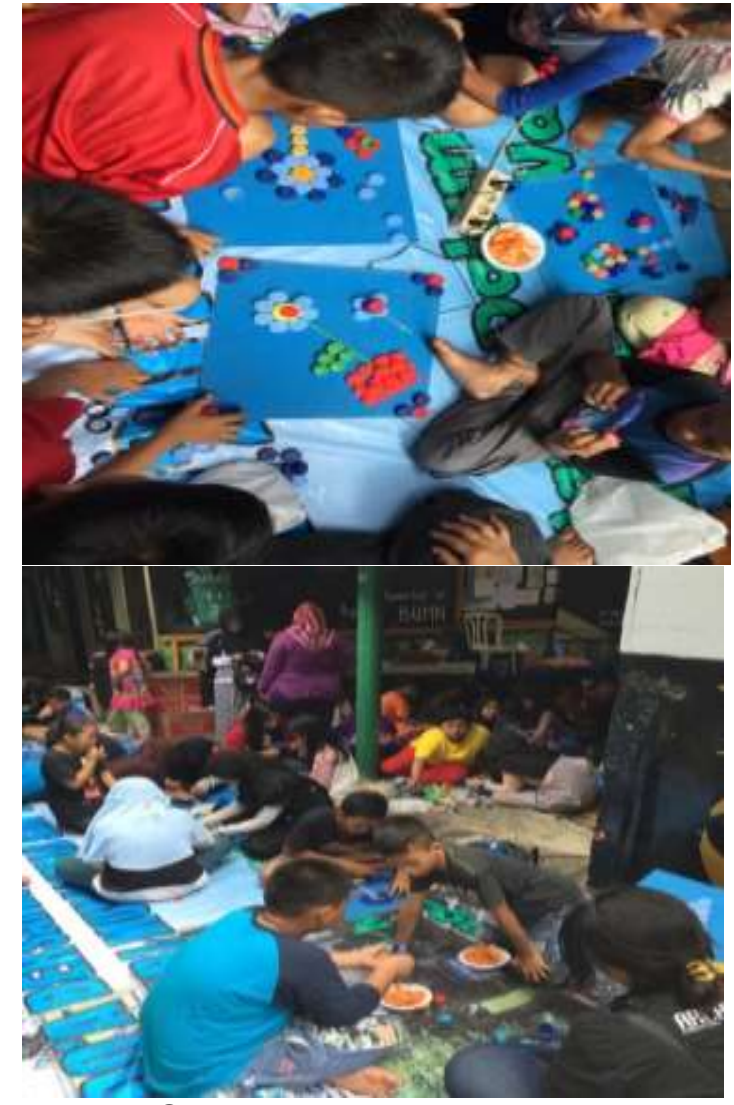

Gambar 6. Pelaksanaan Lomba Kreativitas Karya Seni \& Kerajinan

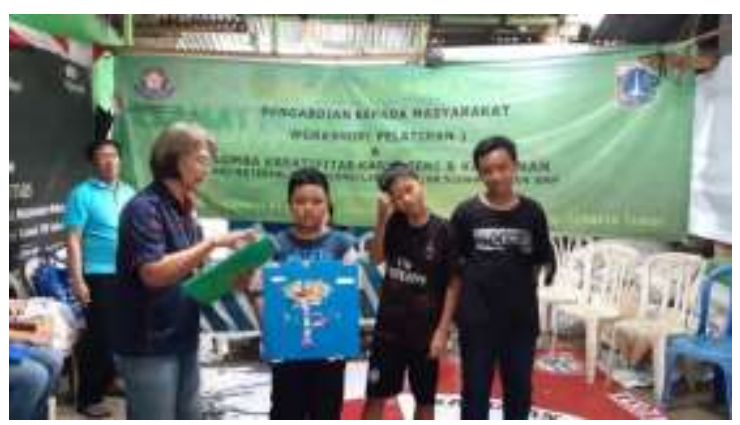

Gambar 7. Pemenang Lomba Kreativitas Karya Seni \& Kerajinan

\section{SIMPULAN}

Simpulan Kesimpulan yang dapat dihasilkan dari kegiatan ini adalah :

a. Secara umum, tingkat partisipasi masyarakat yang didukung toleransi dan gotong royong masih cukup kental, hanya saja perlu proses pendampingan dalam rangka menemukan tingkat Kebutuhan dan rencana pogram yang lebih terarah, tepat sasaran dan bermanfaat untuk masyarakat banyak.

b. Peningkatan Kreativitas Karya Seni \& Kerajinan Dari Material Daur Ulang/Limbah diharapkan dapat meningkatkan kualitas lingkungan, secara Kontekstual.

c. Sumber daya setempat masih menjadi potensi utama dalam mengembangkan kawasan dengan mengedepankan potensi lokal diharapkan mampu menjadikan program pelaksanaan kegiatan berlangsung secara bekesinambungan dan berkelanjutan.

\section{UCAPAN TERIMA KASIH}

Terima kasih yang sebesar-besarnya tidak lupa kami ucapkan kepada Universitas Kristen Indonesia sebagai sumber dana dari Program Pengabdian Pada Masyarakat yang berjudul Pemanfaatan Material daur Uang untuk pengembangan karya seni dan kerajinan di Kelurahan Kebon Pala Kecamatan Makasar Jakarta Timur. 
Volume 2, Nomor 1, Tahun 2020 Hal 301 - 311

\section{REFERENSI}

Pemilahan Sampah Berbasis

Damanhuri, E dan Padmi, T. 2006.

Pengumpulan Terjadwal. Jurnal Pengelolaan Sampah. Diktat Kuliah Infrastruktur dan Lingkungan Binaan Dep. Teknik Lingkungan ITB. Bandung. Vol. II. No. 2 Desember 2006.

Rahardiyan B. dan Murdeani. D. A. 2006. Sikap Masyarakat Terhadap Undang-Undang Nomor 18 Tahun 2008 tentang Pengelolaan Sampah. 